\title{
Comparação de Sistemas de Avaliação de Dietas para Bovinos no Modelo de Produção Intensiva de Carne. Suplementação do Pasto para Vacas na Estação Seca ${ }^{1}$
}

\section{Alexandre Amstalden Moraes Sampaio², Rodolfo Marques de Brito ${ }^{3}$, Luciano Luz Morgan de Aguiar 4 , Paulo Rossi Junior ${ }^{5}$, Geraldo Maria da Cruz ${ }^{6}$, Maurício Mello Alencar ${ }^{6}$, Pedro Franklin Barbosa ${ }^{6}$, Rogério Taveira Barbosa6}

\begin{abstract}
RESUMO - Foram utilizadas 30 vacas da raça Canchim com 50 meses de idade e peso corporal médio de $471 \mathrm{~kg}$, que receberam suplemento alimentar durante a estação seca de 1998, objetivando avaliar a precisão no desempenho estimado por diferentes sistemas de avaliação de dietas. Os suplementos, à base de silagem de milho, milho, polpa cítrica peletizada, farelo de algodão, farelo de soja e soja integral, seguiram as recomendações do Sistema de Proteína Metabolizável (MP); do Sistema de Proteína e Carboidratos Líquidos de Cornell (CNCPS); e do Sistema de Proteína Digestível no Intestino (PDI), para manutenção do peso corporal. A variação diária de peso corporal obtida não diferiu entre os tratamentos CNCPS, MP e PDI, com médias de 0,34; 0,33; e 0,19 kg/cab, respectivamente. Quando a produção de carne constituiu-se no objetivo único do sistema produtivo, a análise econômica revelou saldo de $\mathrm{R} \$ 22,00$; R\$-44,73; e R \$47,27/ha/ano, para os sistemas CNCPS, MP e PDI, respectivamente. Concluiu-se que os suplementos avaliados pelos sistemas proporcionaram resultados de desempenho animal compatíveis com os estimados.
\end{abstract}

Palavras-chave: bovinos, exigências, farelo de algodão, farelo de soja, silagem de milho

\section{Comparison of Diet Evaluation Systems for Cattle in an Intensive Beef Production Model. Supplementation of Pastures to Cows in the Dry Season}

\begin{abstract}
Thirty Canchim cows, averaged $471 \mathrm{~kg}$ of body weight and 50 months old, were fed with supplement during the dry season of 1998, in order to evaluate the precision of the predicted performance for different systems of diet evaluation. The supplements were composed of corn silage, corn grain, citrus pulp, cottonseed meal, soybean meal and whole soybean, in agreement with the recommendations of the Metabolizable Protein System (MP); Cornell Net Carbohydrate and Protein System (CNCPS); and Intestine Digestible Protein System (PDI), for body weight maintenance. The daily body weight change obtained did not differ among treatments CNCPS, MP and PDI, with 0.34; 0.33 ; and $0.19 \mathrm{~kg} / \mathrm{head}$, respectively. When the meat production was the sole objective, the economic analysis revealed R \$22.00; R \$-44.73; and R \$47.27/ha/year for MP, CNCPS and PDI systems, respectively. It was concluded that the adjusted supplements provided compatible results with the estimated animal performance.
\end{abstract}

Key Words: beef cattle, corn silage, cottonseed meal, requirements, soybean meal

\section{Introdução}

A maior competitividade da bovinocultura de corte, frente a outras modalidades de exploração agropecuária, depende da máxima eficiência de produção e do aumento da produtividade, principalmente em locais com elevado custo da terra. O bom planejamento das atividades, em função da correta tomada de decisões e da redução dos custos de produção, é que selecionará os criadores e os confinadores capazes de obter maiores lucros e, portanto, permanecer na atividade. Este planejamento depende intimamente do desempenho animal a ser obtido no final da cadeia produtiva, como resultado da interação entre os requerimentos do animal e a disponibilidade de nutrientes da dieta. Assim, estimar os requerimentos do animal e ajustar-lhes uma dieta adequada têm sido alvo de inúmeras pesquisas, que resultaram na elaboração de diversos sistemas de avaliação de dietas para bovinos, como por exemplo o Sistema de Proteína Metabolizável - MP (AGRICULTURAL AND FOOD RESEARCH COUNCIL - AFRC, 1993); o

\footnotetext{
1 Pesquisa financiada pela FAPESP (processo no. 97/06792-1)

2 Zootecnista. Prof. Adjunto Depto. Zootecnia - FCAV/UNESP Jaboticabal (SP). V.a. Prof. Paulo D. Castellane s/n - CEP 14884-900. Fone: (16)3209-2684 /2685 / 2686. Bolsista CNPq. E.mail: sampaio@fcav.unesp.br

3 Zootecnista. Pós-graduando (Doutorado) em Zootecnia FCAV. Bolsista FAPESP. E.mail: rmbrito@fcav.unesp.br

4 Zootecnista

5 Zootecnista. Professor UFPR- R.XV Novembro,1299 CEP 8060000 Curitiba(PR). E.mail: parossi@agrarias.ufpr.br

6 Embrapa Pecuária Sudeste - Rod. W. Luiz km 234 - Cx.Postal 339 - São Carlos(SP). http://www.cppse.embrapa.br
} 
Sistema de Proteína e Carboidratos Líquidos de Cornell - CNCPS (FOX et al., 1992); e o Sistema de Proteína Digestível no Intestino - PDI (JARRIGE, 1990). Infelizmente, os dados empregados no desenvolvimento destes modelos foram obtidos em condições diferentes das nacionais, o que vem motivando estudos sobre sua aplicação e utilização no Brasil. Os trabalhos têm se concentrado principalmente na avaliação de alimentos tipicamente nacionais para serem empregados nos diferentes sistemas, sendo raros os trabalhos que objetivaram validar a predição do desempenho animal de acordo com a estimativa de requerimentos e o ajuste de dietas, como fizeram LANNA et al. (1994) e MORAIS et al. (1996). Assim, tornou-se objetivo deste trabalho comparar e avaliar o desempenho de matrizes de corte, em pastagem de estação seca suplementada segundo as recomendações de diferentes sistemas de avaliação de dietas.

\section{Material e Métodos}

Foram utilizadas 30 vacas da raça Canchim com média de idade de 50 meses, prenhez positiva, divididas em três grupos de 10 animais, mantidos em três módulos de pastejo rotativo intensivo de Brachiaria brizantha cv. Marandu ( 3 ha/módulo), nos quais receberam a suplementação de inverno de acordo com as recomendações de cada um dos três sistemas: Sistema de Proteína Metabolizável - MP (AFRC, 1993); o Sistema de Proteína e Carboidratos Líquidos de Cornell - CNCPS (FOX et al., 1992) e o Sistema de Proteína Digestível no Intestino - PDI (JARRIGE, 1990). O sorteio dos animais nos tratamentos experimentais obedeceu critérios de peso e condição corporal, tempo de gestação e ordem de parição, procurando-se obter grupos tão homogêneos quanto possível, reduzindo a interferência destas variáveis na experimentação. Na segunda metade do mês de maio, os animais foram pesados e começaram a receber a alimentação suplementar à pastagem, permanecendo em regime de rodízio (seis dias de ocupação x 42 dias de descanso) nos piquetes de pastejo. Cada piquete ( 0,375 ha) recebeu, na estação chuvosa anterior ao ensaio, aplicação de $130 \mathrm{~kg} \mathrm{~N} / \mathrm{ha} / \mathrm{ano}$, parcelados em quatro adubações. Em virtude da pressão de pastejo média adotada durante o período chuvoso, estimou-se que os piquetes de pastejo apresentavam resíduo médio de $760 \mathrm{~kg} \mathrm{MS} / \mathrm{ha}$, ao início de cada período de ocupação. Para auxiliar o ajuste das fórmulas dos suplementos, a forragem dos piquetes foi previamente amostrada (método do quadrado) e a análise laboratorial das amostras compostas indicou que o capim-Marandu apresentou 4,93\% PB na matéria seca. O teor energético e a ingestão média da forrageira foram estimados em $40 \%$ NDT e 1,3\% do peso corporal, respectivamente. Os suplementos iniciais foram ajustados em cada sistema visando a atender às exigências de manutenção do peso corporal e foram compostos por silagem de milho, polpa cítrica peletizada, farelo de soja e soja integral. Ao final do primeiro período de ensaio (90 dias), quando as vacas dos lotes experimentais atingiram média de seis meses de gestação, os animais foram pesados e os suplementos reajustados para atender as exigências de manutenção de peso corporal e gestação, sendo que a polpa cítrica foi substituída por milho grão, conforme indicado na Tabela 1, permanecendo desta forma até o final do segundo período que teve duração de 50 dias.

$\mathrm{O}$ ajuste dos suplementos nos tratamentos MP e PDI seguiu o balanceamento por custo minimizado, sem contudo preterir as recomendações dos princípios de alimentação preconizados pelos sistemas. No caso do CNCPS, não houve formulação por custo minimizado, porém buscou-se atender ao máximo de requisitos para que o suplemento guardasse as características do sistema de avaliação. Isto explica o fato dos suplementos experimentais não possuírem todos os alimentos em suas fórmulas finais, sendo também possível notar as diferenças nas dietas suplementares em razão da variação das recomendações de aporte nutricional preconizada por cada um dos ajustes. As características e padrões raciais das fêmeas Canchim seguiram as informações de CRUZ et al. (1997) e de ALENCAR (1997). A avaliação da condição corporal dos animais seguiu a escala de 1 (muito magra) a 9 (muito gorda), descrita pelo NATIONAL RESEARCH COUNCIL - NRC (1996). As médias das variáveis estudadas foram analisadas segundo um delineamento inteiramente casualizado ( 3 tratamentos; 10 repetições) e foram comparadas pelo teste de Tukey, a $5 \%$ de significância, por intermédio do seguinte modelo matemático (BANZATTO e KRONKA, 1992): $\mathrm{X}_{\mathrm{ij}}=\mathrm{m}+\mathrm{t}_{\mathrm{i}}+\mathrm{e}_{\mathrm{ij}}$, em que $X_{i j}=$ valor do parâmetro observado na parcela que recebeu o tratamento $i(i=1, \ldots, 3)$ na repetição $j$ $(\mathrm{j}=1, \ldots, 10) ; \mathrm{m}=$ média geral do parâmetro no experimento; $\mathrm{t}_{\mathrm{i}}=$ efeito devido ao tratamento $\mathrm{i}(\mathrm{i}=1$, $2,3)$ que foi aplicado na parcela; $\mathrm{e}_{\mathrm{ij}}=$ efeito devido ao acaso na parcela que recebeu o tratamento $\mathrm{i}(\mathrm{i}=1, \ldots, 3)$ na repetição $\mathrm{j}(\mathrm{j}=1, \ldots, 10)$. $\mathrm{O}$ peso corporal das matrizes, obtido em cada pesagem, foi corrigido de acordo com FERREL et al. (1976), visando minimizar 
Rev. bras. zootec.

Tabela 1 - Quantidades de alimentos fornecidas ( $\mathrm{kg} \mathrm{MS/cab/dia)} \mathrm{para} \mathrm{manutenção} \mathrm{corporal} \mathrm{(período} \mathrm{1)} \mathrm{e} \mathrm{manutenção} \mathrm{+}$ gestação (período 2) de vacas Canchim, de acordo com as recomendações de cada tratamento

Table 1 - Feeds amounts offered ( $\mathrm{kg}$ DM/head/day) for body maintenance (period 1) and maintenance + gestation (period 2) of Canchim cows, in agreement with each treatment recommendations

\begin{tabular}{|c|c|c|c|c|c|c|}
\hline \multirow{2}{*}{$\begin{array}{l}\text { Tratamentos } \\
\text { Treatments } \\
\text { Alimento } \\
\text { Feed }\end{array}$} & \multicolumn{2}{|c|}{ CNCPS $^{1}$} & \multicolumn{2}{|c|}{$\mathrm{MP}^{2}$} & \multicolumn{2}{|c|}{$\mathrm{PDI}^{3}$} \\
\hline & $\begin{array}{c}\text { Período } 1^{4} \\
\text { Period } 1\end{array}$ & $\begin{array}{c}\text { Período } 2 \\
\text { Period } 2\end{array}$ & $\begin{array}{c}\text { Período } 1 \\
\text { Period } 1\end{array}$ & $\begin{array}{c}\text { Período } 2 \\
\text { Period } 2\end{array}$ & $\begin{array}{l}\text { Período } 1 \\
\text { Period } 1\end{array}$ & $\begin{array}{c}\text { Período } 2 \\
\text { Period } 2\end{array}$ \\
\hline $\begin{array}{l}\text { Sil. de milho } \\
\text { Corn silage }\end{array}$ & 3,00 & 4,00 & 2,19 & 2,38 & 2,80 & 3,82 \\
\hline $\begin{array}{l}\text { Milho grão } \\
\text { Corn grain }\end{array}$ & - & 1,12 & - & 1,43 & - & 0,50 \\
\hline $\begin{array}{l}\text { Farelo de soja } \\
\text { Soybean meal }\end{array}$ & - & - & 0,67 & 0,11 & - & - \\
\hline $\begin{array}{l}\text { Polpa cítrica } \\
\text { Citrus pulp }\end{array}$ & 1,00 & - & 1,83 & - & 1,00 & - \\
\hline $\begin{array}{l}\text { Soja integral } \\
\text { Whole soybean }\end{array}$ & 0,50 & 0,50 & - & 0,89 & 0,59 & 0,55 \\
\hline Total & 4,50 & 5,62 & 4,69 & 4,81 & 4,39 & 4,87 \\
\hline
\end{tabular}

${ }_{1}$ CNCPS - Sistema de Proteína e Carboidratos Líquidos de Cornell (CNCPS - Cornell Net Carbohydrate and Protein System).

2 MP - Sistema de Proteína Metabolizável (MP - Metabolizable Protein System).

3 PDI - Sistema de Proteína Digestível no Intestino (PDI - Intestine Digestible Protein System)

4 Período 1 = 0-90 dias; Período $2=91-140$ dias (Period $1=0$-90 days; Period $2=91-140$ days).

a interferência do peso do bezerro e dos anexos fetais sobre o peso do animal.

A avaliação econômica do sistema de produção considerou inicialmente as receitas geradas pelo mesmo, bem como os custos de implantação (fixos) e manutenção (variáveis). No caso dos custos de implantação agruparam-se todos os gastos efetuados dentro dos itens de despesa mais abrangentes: cercas elétricas e convencionais ( $\mathrm{R} \$ 1549,00 / \mathrm{ha})$; material hidráulico ( $\mathrm{R} \$ 323,00 / \mathrm{ha}$ ); e formação da forrageira ( $\mathrm{R} \$ 328,00 / \mathrm{ha}$ ), totalizando $\mathrm{R} \$ 6600,00 \mathrm{em}$ cada módulo experimental (3 ha). Quanto às receitas, considerou-se os proventos específicos em ambos os tipos de exploração propostos (carne ou tourinhos para reprodução). Cada módulo possuía 10 matrizes, das quais $10 \%$ destas foram descartadas anualmente (abate) cedendo lugar a 20\% das fêmeas oriundas do criatório e normalmente destinadas à reposição, sendo os $80 \%$ restantes destas comercializadas ( $\mathrm{R} \$ 300,00 / \mathrm{cab}$ ). No caso da produção de touros, haveria um aproveitamento de $40 \%$ dos animais que seriam vendidos como reprodutores ( $\mathrm{R} \$ 1500,00 / \mathrm{cab})$ e um descarte de $60 \%$, comercializados para corte ( $\mathrm{R} \$ 380,00 / \mathrm{cab})$. No caso de produção de carne, todos os bezerros (exceto as fêmeas de reposição) seriam comercializados para o abate ( $\mathrm{R} \$ 38,00 /$ arroba). O peso de abate das vacas foi considerado como $500 \mathrm{~kg}$ com preço de $\mathrm{R} \$ 31,00 /$ arroba e rendimento de carcaça quente de $53 \%$. A receita anual calculada para cada tipo de exploração foi de $\mathrm{R} \$ 5887,00$ e R $\$ 3647,00$ para a produção de tourinhos e produção de carne, respectivamente.

\section{Resultados e Discussão}

Os dados obtidos refletiram o equilíbrio entre os diferentes tratamentos em proporcionar resultados coerentes com a condição experimental a que foram submetidos os animais. Como a manutenção do peso corporal foi conseguida com a suplementação fornecida no cocho, a pastagem pôde ser aproveitada em parte para acúmulo de reservas corporais, o que explica o ganho de peso obtido, nos períodos 1 e 2 , bem como no período total, conforme a Tabela 2.

No período 1 , pode-se afirmar que todos os tratamentos foram eficientes em proporcionar os resultados preditos pelos sistemas, enquanto que no período 2 , observou-se um sensível aumento do ganho de peso, apesar de se reduzir a interferência do crescimento fetal. Contudo, a correção do peso da vaca não controlou o ganho em peso devido ao grau de hidratação da fêmea gestante, somando-se a este fato o retorno do crescimento da pastagem e a reformulação das dietas considerando o desenvolvi- 
Tabela 2 - Análise do peso corporal inicial (PCI), ganho de peso corporal (GPC) e condição corporal (CC) de vacas Canchim em pasto suplementado durante a estação seca, de acordo com as recomendações de cada tratamento, e respectivos coeficientes de variação (CV)

Table 2 - Analysis of initial body weight (IBW), body weight gain (BWG) and body condition (BC) of Canchim cows in supplemented pasture during dry season, in agreement with the recommendations of each treatment, and respective coefficients of variation (CV)

\begin{tabular}{|c|c|c|c|c|c|c|}
\hline \multirow[b]{2}{*}{$\begin{array}{l}\text { Tratamento } \\
\text { Treatment }\end{array}$} & \multicolumn{6}{|c|}{$\begin{array}{l}\mathrm{GPC}(\mathrm{kg} / \mathrm{cab} / \mathrm{dia})^{1} \\
B W G(\mathrm{~kg} / \mathrm{head} / \text { day })\end{array}$} \\
\hline & $\begin{array}{c}\text { PCI }(\mathrm{kg})^{2} \\
I B W\end{array}$ & $\begin{array}{l}\text { Período } 1 \\
\text { Period } 1 \\
\end{array}$ & $\begin{array}{l}\text { Período } 2 \\
\text { Period } 2 \\
\end{array}$ & $\begin{array}{l}\text { Período Total } \\
\text { Overall period }\end{array}$ & $\begin{array}{l}\text { CCinicial } \\
\text { Initial } B C\end{array}$ & $\begin{array}{l}\text { CC final } \\
\text { Final } B C\end{array}$ \\
\hline $\mathrm{CNCPS}^{3}$ & 459,0 & 0,14 & $1,17^{\mathrm{a}}$ & 0,34 & 7,5 & 8,0 \\
\hline MP & 484,0 & 0,16 & $1,05^{\mathrm{ab}}$ & 0,33 & 8,1 & 8,2 \\
\hline PDI & 470,0 & 0,06 & $0,76^{\mathrm{b}}$ & 0,19 & 8,0 & 8,0 \\
\hline $\mathrm{CV}(\%)$ & 9,11 & 157,38 & 29,86 & 57,22 & 5,20 & 3,33 \\
\hline
\end{tabular}

${ }_{1}^{1}$ Letras desiguais na coluna indicam valores diferentes pelo teste de Tukey (5\%) (Different letters in column indicate different values by Tukey test [5\%]). 2 Corrigidos de acordo com FERREL et al. (1976) (Corrected according to FERREL et al. [1976]).

3 CNCPS - Sistema de Proteína e Carboidratos Líquidos de Cornell; MP - Sistema de Proteína Metabolizável; PDI - Sistema de Proteína Digestível no Intestino (CNCPS - Cornell Net Carbohydrate and Protein System; MP - Metabolizable Protein System; PDI - Intestine Digestible Protein System).

${ }^{4}$ Avaliada de acordo com o NRC (1996): 1 (muito magra) a 9 (muito gorda) (Evaluated according to NRC [1996]: 1 [emaciated] to 9 [very fat]).

mento do bezerro, que por sua vez, poderia superestimar as reais exigências nutricionais do feto, direcionando possíveis excedentes de nutrientes para o acúmulo de reservas corporais na vaca.

Ao se analisar o período total de experimentação, foi possível notar que não houve diferenças entre os tratamentos, e os ganhos de peso obtidos mantiveram-se em níveis compatíveis com a interação entre os fatores experimentais e os fatores ambientais e fisiológicos citados anteriormente. É preciso ressaltar a semelhança absoluta entre as médias dos sistemas MP e CNCPS, em razão da abordagem marcadamente diferenciada dos princípios nutricionais praticados na nutrição de bovinos. Isto significa que a flexibilidade de manipulação dos ingredientes para confecção de suplementos para matrizes em pastagens pode ser amplamente controlada dentro dos princípios básicos de cada um dos sistemas utilizados. Assim, a confiança em se obter o resultado planejado parece ser elevada e a programação de investimentos financeiros e o estabelecimento do calendário de atividades poderia ser feita com relativa segurança. No intuito de diminuir gastos, JARRIGE (1990) e o AFRC (1993) recomendaram que após a desmama do bezerro, a fêmea cuja prenhez tenha sido seguramente confirmada, poderia receber dietas ajustadas para se obter discreta perda de peso, pois no período pós-desmame, as exigências deste tipo de animal são relativamente baixas e manter as vacas em condição corporal acima de 7 torna-se desnecessário, já que o dispêndio de recursos com esta categoria animal deve ser mínimo. Porém, a literatura alerta para o fato de que a perda de peso não seja demasiadamente intensa e não ultrapasse $0,5 \mathrm{~kg} / \mathrm{cab} / \mathrm{dia}$, o que poderia complicar sobremaneira o parto e o serviço seguintes. Como se trata de um manejo delicado, porém economicamente efetivo, é preciso confiar no regime alimentar e na dieta aos quais os animais serão submetidos. O presente trabalho mostrou que os sistemas constituem-se em potentes ferramentas que possibilitam ao pecuarista, e ao profissional da área, adotar estratégias de manejo e criação de alta tecnologia, sem se expor aos sérios riscos de perdas de capital, oriundos de erros cometidos em função de equivocadas tomadas de decisão.

Os resultados referentes à avaliação da condição corporal das matrizes também estão na Tabela 2, na qual se constata ausência de diferenças nas avaliações inicial e final, refletindo a regularidade do estado de carnes das fêmeas, independentemente do tratamento testado. A condição corporal ao redor de 8 , avaliada conforme o NRC (1996), possibilitou um bom retorno à atividade ovariana dos animais, o que resultou em taxa de concepção de $96,6 \%$ após o término do período de serviço, concordando com os resultados obtidos por OLIVEIRA et al. (1997), os quais verificaram que a suplementação pré-parto reduziu o intervalo parto-cio, comparado com animais que receberam suplementação após o parto e os testemunhas. Faz-se ainda necessário citar o incremento de condição corporal apresentado pelos animais do tratamento CNCPS que refletiu maior aporte nutricional da suplementação, o que possibilitou pequeno acréscimo de reservas corporais, fato também evidenciado pelos ganhos de peso obtidos 
Rev. bras. zootec.

pelos animais do tratamento em questão.

No atual contexto da pecuária de corte, os resultados devem ser analisados em conjunto com as avaliações econômicas referentes aos tratamentos testados. Esta integração de informações possibilitaria a avaliação de alternativas de emprego das técnicas estudadas e ainda propiciaria maiores chances de sucesso quando da adoção das mesmas. Os resultados da análise econômica referente aos três sistemas de nutrição aqui pesquisados foram avaliados sob dois pontos de vista da exploração pecuária do gado de corte: produção de carne e produção de touros cruzados/mestiços.

Constam da Tabela 3 os balanços econômicos gerais de cada um dos módulos de pesquisa, agregando o efeito do custo da suplementação recomendada pelos diferentes sistemas de ajuste, o que forneceu bom indicativo da importância deste fator e ainda esclareceu o diferencial obtido em cada trabalho, de acordo com a abordagem produtiva (carne $\mathrm{x}$ tourinhos) escolhida.
Observou-se que apenas o módulo experimental de produção cujos animais receberam a suplementação ajustada pelo sistema MP proporcionou rentabilidade negativa quando a intensificação do modelo de produção visou à produção de bezerros para corte, com valores de $\mathrm{R} \$ 22,00 ; \mathrm{R} \$-44,73$; e $\mathrm{R} \$ 47,27 / \mathrm{ha} / \mathrm{ano}$, para os sistemas CNCPS, MP e PDI, respectivamente. Embora os tratamentos CNCPS e PDI tenham apresentado resultado positivo, na prática, os valores líquidos que seriam apurados após a venda dos animais são bastante insatisfatórios e a remuneração do capital permaneceu em ao redor de $0,24 \%$ ao mês, bem abaixo da remuneração que poderia ser obtida em outras aplicações no mercado financeiro, ou ainda, em outras formas de uso e exploração da terra. Além disso, ficou evidente a importância que deve ser destinada à escolha do suplemento, pois a simples modificação das características do alimento suplementar foi responsável por tornar um dos módulos de produção

Tabela 3 - Análise econômica da utilização dos sistemas CNCPS, MP e PDI no ajuste de dieta suplementar para vacas da raça Canchim durante o período seco em modelos físico-estruturais de produção de carne ou produção de tourinhos ${ }^{1}$

Table 3 - Economic analysis of CNCPS, MP and PDI systems in adjustment of supplemental diet to Canchim cows during the dry season in an physical and structural models of meat production or sire production

\begin{tabular}{|c|c|c|c|c|c|c|}
\hline \multirow[t]{2}{*}{ Item } & \multicolumn{2}{|c|}{$\mathrm{CNCPS}^{2}$} & \multicolumn{2}{|c|}{ MP } & \multicolumn{2}{|c|}{ PDI } \\
\hline & $\begin{array}{l}\text { Carne } \\
\text { Meat }\end{array}$ & $\begin{array}{l}\text { Touros } \\
\text { Sires }\end{array}$ & $\begin{array}{l}\text { Carne } \\
\text { Meat }\end{array}$ & $\begin{array}{l}\text { Touros } \\
\text { Sires }\end{array}$ & $\begin{array}{l}\text { Carne } \\
\text { Meat }\end{array}$ & $\begin{array}{c}\text { Touros } \\
\text { Sires }\end{array}$ \\
\hline $\begin{array}{l}\text { Custo fixo comum } \\
\text { Common fix cost }\end{array}$ & 660,00 & 660,00 & 660,00 & 660,00 & 660,00 & 660,00 \\
\hline $\begin{array}{l}\text { Custos variáveis comuns } 4 \\
\text { Common variable costs }\end{array}$ & 1922,16 & 1922,16 & 1922,16 & 1922,16 & 1922,16 & 1922,16 \\
\hline $\begin{array}{l}\text { Custo de suplementação } \\
\text { Supply cost }\end{array}$ & 796,13 & 796,13 & 985,02 & 985,02 & 724,60 & 724,60 \\
\hline $\begin{array}{l}\text { Subtotal } \\
\text { Juros s/capital investido }\end{array}$ & $\begin{array}{r}3378,29 \\
202,70\end{array}$ & $\begin{array}{r}3378,29 \\
202,70\end{array}$ & $\begin{array}{r}3567,18 \\
214,03\end{array}$ & $\begin{array}{r}3567,18 \\
214,03\end{array}$ & $\begin{array}{r}3306,76 \\
198,41\end{array}$ & $\begin{array}{r}3306,76 \\
198,41\end{array}$ \\
\hline $\begin{array}{l}\text { Interest on invested capital } \\
\text { Total custos }\end{array}$ & 3580,99 & 3580,99 & 3781,21 & 3781,21 & 3505,17 & 3505,17 \\
\hline $\begin{array}{l}\text { Total costs } \\
\text { Receita } \\
\text { Income }\end{array}$ & 3647,00 & 5887,00 & 3647,00 & 5887,00 & 3647,00 & 5887,00 \\
\hline $\begin{array}{l}\text { Líquido } \\
\text { Netprofit }\end{array}$ & 66,01 & 2306,01 & $-134,21$ & 2105,79 & 141,83 & 2381,83 \\
\hline $\begin{array}{l}\text { Remuneração mensal (\%) } \\
\text { Monthly remuneration }\end{array}$ & 0,15 & 4,23 & $-0,30$ & 3,76 & 0,33 & 4,42 \\
\hline
\end{tabular}

\footnotetext{
1 Valores expressos em R\$ (reais), exceto Remuneração mensal; $R \$ 2,00=$ US $\$ 1.00$.

2 CNCPS - Sistema de proteína e carboidratos líquidos de Cornell; MP - Sistema de Proteína Metabolizável; PDI - Sistema de Proteína Digestível no Intestino.

3 Depreciação da infra-estrutura - $\mathrm{R} \$ 660,00$.

${ }^{4}$ Adubo (130 kg N/ha/ano) - R\$ 877,50; Peão (0,33 homens/ano) - R\$866,66; Medicamentos (ano) - R\$ 100,00; Sal mineral (260 kg/ano) $\mathrm{R} \$ 78,00$.

Values are expressed in $R \$$ (reais), except "Montlhy remuneration". R $\$ 1,00=U S \$ 2.00$

CNCPS - Cornell Net Carbohydrate and Protein System; MP - Metabolizable Protein System; PDI - Intestine Digestible Protein System.

Facilities maintenance - $R \$ 660,00$.

Fertilizer (130 kg N/ha/year) - R\$877,50; Employee (0,33 man/year) - R\$866,66; Veterinary drugs (year) - $R \$ 100,00 ;$ Mineral premix (260 kg/year).
} 
economicamente inviável. No caso de produção de animais para a reprodução, os lucros líquidos foram de $\mathrm{R} \$ 768,67$; $\mathrm{R} \$ 701,93$; e $\mathrm{R} \$ 793,94 / \mathrm{ha} /$ ano para os sistemas CNCPS, MP e PDI, respectivamente, indicando o grande potencial econômico desta modalidade de exploração de bovinos de corte. Note-se que neste caso, a taxa de remuneração mensal sobre o capital investido esteve ao redor de $4,13 \%$ ao mês, o que pode representar significativa diferença em relação a outras aplicações financeiras, considerando que à ocasião da realização deste trabalho, a mais popular aplicação - caderneta de poupança proporcionou aos investidores taxas mensais ao redor de $0,60 \%$. É preciso ressaltar que o sensível diferencial em relação a este valor de mercado quando se considera as taxas de remuneração mensal obtidas no sistema destinado à produção de tourinhos, quase sete vezes maior do que a caderneta de poupança, constitui tal atividade em atraente opção para investimentos que visam à multiplicação substancial do capital empregado, já que a rentabilidade gerada aproximou-se de R \$750,00/ha/ano. Em ambos os modelos produtivos avaliados, carne ou touros, note-se o diferencial produzido entre os tratamentos com rentabilidade positiva, pela variação no custo do suplemento utilizado: o sistema PDI proporcionou rentabilidades superiores em até $4,5 \%$ ao tratamento CNCPS, sem reflexos nos resultados de desempenho. Novamente, este resultado atestou a vital importância que deve ser despendida em relação ao manejo nutricional dos animais que invariavelmente deve agregar baixo custo e desempenho adequados.

\section{Conclusões}

A suplementação do pasto para vacas de corte durante o período seco, no modelo de pastejo rotacionado intensivo, utilizando os sistemas de nutrição CNCPS, MP e PDI, proporcionou desempenho animal semelhante e pode ser adotada como eficiente estratégia para se alcançar bom desempenho reprodutivo. Os sistemas constituem-se em ferramentas alternativas que possibilitam ao pecuarista e ao profissional da área adotar estratégias de manejo com precisão. A modalidade comercial da exploração intensiva de vacas de corte é fator determinante da rentabilidade propiciada por tal modelo de produção, devendo ser rigorosamente considerada no caso de adoção do mesmo, o que poderá determinar de forma decisiva o sucesso obtido na atividade.

\section{Referências Bibliográficas}

AGRICULTURAL AND FOOD RESEARCH COUNCIL AFRC. 1993. Energy and protein requirements of ruminants. Wallingford: CAB International. 159p.

ALENCAR, M.M. Pesquisa na raça Canchim. In: CONVENÇÃO NACIONAL DA RAÇA CANCHIM, 3, 1997, São Carlos. Anais... São Carlos: EMBRAPA-CPPSE/São Paulo: ABCCAN. p.77-93.

BANZATTO, D.A., KRONKA, S.N. 1992. Experimentação agrícola. 2.ed., Jaboticabal: Funep. 247p.

CRUZ, G.M., ALENCAR, M.M., TULLIO, R.R. 1997. Produção e composição do leite de vacas das raças Canchim e Nelore. R. Bras. Zootec., 26(5):887-893.

FERREL, C.L., GARRETT, W.N., HINMAN, N. 1976. Growth, development and composition of udder and gravid uterus of beef heifers during pregnancy. J. Anim. Sci., 42(6):1477-1489.

FOX, D.G., SNIFFEN, C.J., O’CONNOR J.D. et al. 1992. A Net Carbohydrate and Protein System for evaluating cattle diets. III - Cattle requirements and diet adequacy. J. Anim. Sci., 70(11):3578-96.

JARRIGE, R. 1990. Alimentación de bovinos, ovinos y caprinos. Madri: Mundi-Prensa. 431p.

LANNA, D.P.D., BOIN, C., FOX, D.G. Validação do CNCPS e do NRC (1984) para estimativa dos requerimentos nutricionais e desempenho de zebuínos em crescimento. In: REUNIÃO ANUAL DA SOCIEDADE BRASILEIRA DE ZOOTECNIA, 31, 1994, Maringá. Anais... Maringá: SBZ, 1994. p.480.

MORAIS, J.P.G., LANNA, D.P.D., BOIN, C. et al. Níveis de proteína em dietas de bagaço hidrolisado - Validação dos requerimentos estimados pelo CNCPS. In: REUNIÃO ANUAL SOCIEDADE BRASILEIRA DE ZOOTECNIA, 33, 1996, Fortaleza. Anais... Fortaleza: SBZ, 1996. v.3, p.286-7.

NATIONAL RESEARCH COUNCIL - NRC. 1996. Nutrient requirements of beef cattle. 7.ed. Washington: National Academic Press. 242p.

OLIVEIRA, B.D., GAMBARINE, M.L., TONIOLO, G.H. 1997. Efeitos da suplementação nutricional pré e pós-parto e da condição corporal ao parto sobre a reprodução em vacas de corte. Rev. Bras. Reprod., (21)2:112-117.

Recebido em: 26/12/00

Aceito em: 19/04/01 